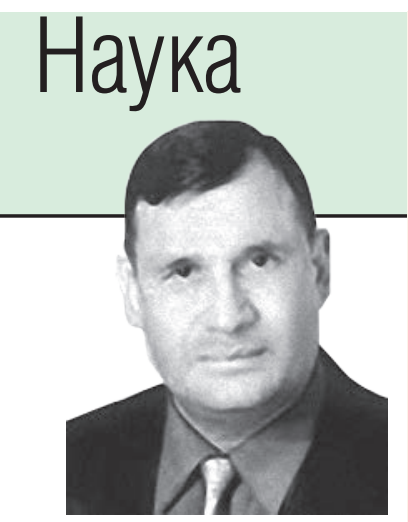

П.Г. ГРАБОВЫЙ Доктор экон. наук, профессор, завкафедрой «Организация строительства и управление недвижимостью",

директор Института градорегулирования и управления Недвижимостью ФГБОУ ВПО «Московский государственный строительный университет». Автор более 100 научных публикаций.

E-mail: igun@mgsu.ru
И

коммунальной сферы для частных операторов состоит в условиях инвестирования объектов коммунальной инфраструктуры как на принципах вложения, так и долгосрочной аренды, а именно: за счет государственной и муниципальной помощи на безвозвратных или льготных условиях; в возможности приобретения в собственность тех строящихся объектов по электро-, тепло-, водоснабжению и водоотведению, которые не вошли в состав концессионного соглашения с гарантией возврата своих инвестиций с учетом определенной концессионным соглашением доли процентов. Одним из инструментов привлечения инвестиций является применение новых методов тарифного регулирования и различных договорных моделей.

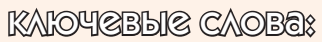

государственная политика развития объектов коммунальной инфраструктуры, инвестиционная привлекательность коммунальной сферы, условия инвестирования и владения объектами коммунальной инфраструктуры, концессионные соглашения, инвестиционная программа организации коммунального комплекса, методы тарифного регулирования, регуляторный договор, вид бюджетных инвестиций.

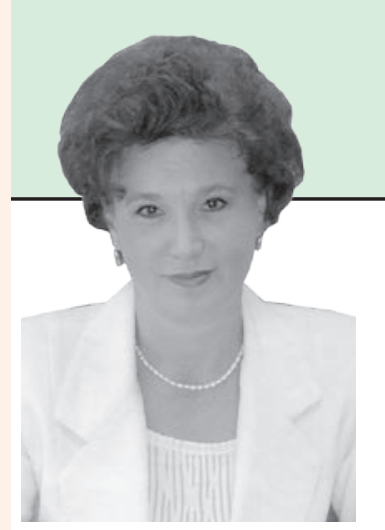

И.П. МАЛИКОВА

Кандидат экон. наук, докторант кафеоры «Организация строительства и управление недвижимостью» ФГБОУ ВПО «Московский государственный строительный университет", генеральный директор $3 А О$ «АКЦ Жилкомаудит». Автор более 30 научных публикаций по проблеме модернизации и тарифной политики городского коммунального комплекса.

E-mail:

osun_kaf@mgsu.ru
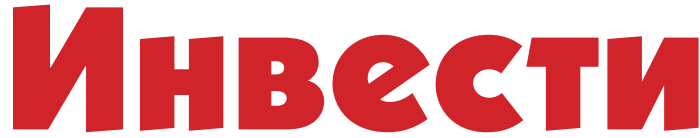
Lи०Hная при BлекательHОсть жипищно-коммунапьной сфер)

\section{Общая часть}

Основные варианты участия частных, государственных и муниципальных инвесторов в инвестиционных проектах в жилищном строительстве необходимо рассматривать в рамках развития объектов коммунальной инфраструктуры, одновременно предполагается разрабатывать механизмы привлечения инвестиций в указанные проекты. Инвестирование в жилищное строительство представляет собой социальную задачу для органов власти всех уровней. Частные инвесторы заинтересованы в нем в силу того, что могут получить прибыль от продажи жилья. Размер последней зависит от рыночных условий покупки жилья, которые напрямую связаны с инвестиционной привлекательностью проектов жилищного строительства, зависят от целей этих проектов и возможностей их реализации. 
Однако привлечение инвестиций для развития и модернизации объектов коммунальной инфраструктуры возможно только при условии обеспечения привлекательности соответствующих инвестиционных проектов со стороны государства. Так определены цели, для достижения которых к 2014 году предполагается создать законодательную базу на федеральном уровне, которая будет регулировать различные механизмы реализации инвестиционной деятельности в жилищно-коммунальной сфере (ЖКС). В качестве наиболее значимых задач определены:

- формирование инвестиционной составляющей в тарифах организаций коммунального комплекса и платы за подключение объектов инженерной инфраструктуры с учетом инвестиций в целях модернизации инфраструктуры;

- установление обязанности органов местного самоуправления утверждать программы комплексного развития своих территорий в плане расширения жилищного строительства и развития и модернизации объектов коммунальной инфраструктуры, на то и другое предполагается направить средства из бюджета;

- внесение изменений в бюджетное законодательство для установления форм бюджетных инвестиций в ЖКС, мер их стимулирования и процедур контроля;

- установление показателей эффективности того, как региональные и муниципальные органы власти управляют объектами коммунальной инфраструктуры, в частности стимулировать их принимать решения по результатам эксплуатации таких объектов частными операторами после приватизации;

- развитие концессионных соглашений и других форм государственно-частного партнерства (ГЧП) для привлечения частных инвестиций в развитие таких объектов;

- изменение правил формирования тарифной политики, которые должны предусматривать гарантии возврата инвестированного капитала для частных инвесторов.

Создаваемая законодательная база позволит привлечь в сферу управления объектами коммунальной инфраструктуры частных операторов, а следовательно, и частные инвестиции.

Инвестиционная привлекательность коммунальной сферы обосновывается следующими вариантами развития объектов коммунальной инфраструктуры, которыми управляют частные операторы:

- Частные операторы могут приобрести в собственность объекты коммунальной инфраструктуры, строящиеся взамен изношенных муниципальных, за счет средств потребителей, ко- торые оплачивают в том числе инвестиционную составляющую жилищно-коммунальных услуг, и платы за подключение объектов, возводимых застройщиками, к существующей инфраструктуре. Таким образом, частный оператор, зашедший на рынок электрической, тепловой энергии, воды, услуг водоотведения, становится владельцем активов основных средств в виде объектов коммунальной инфраструктуры, созданных за счет средств потребителей и застройщиков.

- Условия концессионного соглашения, касающегося владения объектами коммунальной инфраструктуры, позволяют концессионеру приобрести в собственность те объекты коммунальной инфраструктуры, которые концессионер строит в рамках электро-, тепло-, водоснабжения потребителей и оказания им услуг водоотведения, но они не включаются в состав объектов концессионного соглашения. Кроме того, концессионеру, инвестирующему свои средства в объекты коммунальной инфраструктуры, дается гарантия их возврата с учетом определенной концессионным соглашением доли процентов.

Условия инвестирования в развитие объектов коммунальной инфраструктуры с возможностью привлечения бюджетных инвестиций позволяют частным операторам пользоваться такой государственной и муниципальной помощью на безвозвратных или льготных условиях, в результате частные операторы заинтересованы в приобретении активов, с которыми они работают.

Любые частные инвестиции в объекты коммунальной инфраструктуры приводят к положительному эффекту для инвестора: в его распоряжении оказываются результаты таких инвестиций, прибыль от владения объектами коммунальной инфраструктуры и /или от ее эксплуатации. Инвестиционная привлекательность и гарантия возврата инвестированного капитала наиболее востребованы инвесторами, заинтересованными участвовать в проекте.

Проводимая в настоящий период государственная инвестиционная политика в ЖКС предусматривает следующие распространенные мероприятии:

- заключение договоров долгосрочной аренды либо концессионных соглашений с собственником объектов инфраструктуры;

- согласование уровня тарифов на период возврата инвестиций;

- предоставление органами власти гарантий (поручительств) по кредитам;

- софинансирование объектов коммунальной инфраструктуры за счет бюджетных средств;

- выполнение частным оператором условий
Jффективное

нтикризисное

правление 
концессионного соглашения по срокам окупаемости, показателям рентабельности;

- предоставление инвесторам льгот со стороны органов власти.

Bсе перечисленное снижает основные риски участия частных операторов в инвестиционных проектах в ЖКХ, сокращает стоимость привлечения заемных средств и увеличивает показатели инвестиционной привлекательности проектов. Несомненно, в будущем ГЧП как механизм сотрудничества государства и частного оператора станет основным инструментом достижения устойчивого экономического роста страны, однако пока можно говорить лишь о начале формирования практики его применения. Этот инструмент позволит реализовать глобальные инфраструктурные проекты при условии проведения сбалансированной государственной инвестиционной политики, направленной на использование сильных сторон государственного и частного секторов.

\section{Формирование \\ инвестиционных \\ нрограмм ортамизаний \\ коммунаnьното компиекса}

Деятельность организаций коммунального комплекса (ОКК), эксплуатирующих объекты инфраструктуры, предназначенные для энерго-, тепло-, газо-, водоснабжения и водоотведения в интересах потребителей, подлежит государственному регулированию органами исполнительной власти субъектов Российской Федерации, эти же органы устанавливают и регулируют тарифы для ОКК. Такой принцип ограничивает ОКК в определении финансовых потребностей для обеспечения собственной работы в период ее выполнения. Для регулирования деятельности ОКК с 2006 года законодательно предусмотрено формирование инвестиционных программ (ИП) по определенным правилам, с учетом этих программ рассчитываются тарифы.

ИП разрабатываются и реализуются для достижения нескольких целей, к числу которых отнесены:

- реализация программы комплексного развития муниципального образования (МО);

- обеспечение потребностей жилищного и промышленного строительства;

- повышение качества производимых товаров, услуг;

- снижение издержек на производство товаров, услуг;

- улучшение экологической ситуации на территории муниципального образования и др. ется при помощи целевых индикаторов, которые представляют собой характеристику состояния и развития систем коммунальной инфраструктуры (СКИ), условий их эксплуатации, которую необходимо обеспечить за счет реализации ИП. Основу характеристики составляют:

- карты и схемы планируемого размещения объектов строительства, иные документы территориального планирования, содержащие:

- перечень строительных площадок;

- перечень зданий, сооружений по адресам;

- максимальную планируемую нагрузку для подключения каждой из площадок, зданий, сооружений;

- планируемые сроки подключений каждого объекта;

- информация и консультации организацийзастройщиков;

- информация от потребителей товаров, услуг ОКК, которую собирают на основе запросов, жалоб, претензий к ОКК;

- информация по финансовой и производственной деятельности от ОКК;

- информация об ОКК:

- ее финансовое состояние;

- показатели производственной программы;

- показатели статистического наблюдения.

Целевые индикаторы сгруппированы по критериям:

- надежность снабжения;

- сбалансированность СКИ;

- доступность товаров и услуг для потребителей;

- эффективность деятельности ОКК;

- соблюдение экологических требований.

Они определяются на отдельных этапах (промежуточные значения) и после завершения реализации ИП.

Способы обеспечения финансовых потребностей ОКК, необходимых для реализации ее ИП, выбирает орган, регулирующий тарифы, по согласованию с представительным органом МО. При этом учитываются:

- оценка доступности товаров и услуг ОКК для потребителей;

- оценка результатов реализации ИП ОКК:

- для населения МО;

- для потребителей товаров и услуг отдельных видов ОКК на всей территории МО;

- для лиц, осуществляющих строительство и (или) реконструкцию зданий, строений, сооружений, иных объектов;

- установленные предельные показатели.

Таким образом, расходы на развитие производства в виде инвестиционной составляющей учитываются регулирующим тарифы органом 
в составе регулируемых тарифов ОКК в соответствии с основами ценообразования для них.

Источниками финансирования для ИП могут быть любые средства:

- собственные средства организации, разработавшей ИП;

- любые заемные средства, расходы на возврат и обслуживание которых орган регулирования тарифов должен учитывать с того момента, как они направлены на реализацию программы, в том числе при расчете регулируемых тарифов (цен) на последующие расчетные периоды в течение всего согласованного срока окупаемости ИП.

\section{Инструменты привлечения инвестиций}

Для решения задачи привлечения инвестиций в коммунальную сферу ключевое значение имеет переход от применяемых в настоящий период методов формирования тарифов путем экономического обоснования затрат ОКК в течение одного (финансового) года к методам долгосрочного регулирования. К последним отнесены методы доходности инвестированного капитала, индексации тарифов и сравнения аналогов.

Метод доходности инвестированного капитала - метод привлечения инвестиций путем создания механизма возврата вложенных инвестором средств с учетом дохода от вложений. Ключевое отличие метода доходности инвестированного капитала от привычного метода экономического обоснования затрат заключается в том, что инвестиции возвращаются не сразу, а как средства, полученные по этому тарифу в виде амортизации и инвестиционной составляющей в прибыли в течение долгосрочного периода, равного сроку возврата капитала (например, в энергетике это 35 лет, в теплоснабжении 20 лет). Таким образом, инвестиции, вложенные в инфраструктурный объект, компания будет окупать в течение довольно длительного периода. Метод доходности инвестированного капитала рассчитан на долгосрочную перспективу (минимум 20 лет), позволяет определить заведомо известную величину изменения регулируемых тарифов ОКК, а значит, он является стратегически важным.

Метод индексации - долгосрочный метод регулирования, предполагающий утверждение неизменных параметров на весь долгосрочный период, задает темп снижения подконтрольных затрат, в течение пяти лет организация сможет оставлять себе средства, сэкономленные за счет реализации мероприятий программ энергосбережения, повышения энергетической эффективности, а также оптимизации затрат.
Метод сравнения аналогов - метод, основу которого составляет определение базового уровня операционных расходов регулируемой организации с применением метода сравнения аналогов по всем подобным существующим организациям. По сути, строится модель, которая определяет соотношение затрат и определенных характеристик, по которым проводится сравнение. В соответствии с коэффициентами для каждой конкретной организации рассчитывается уровень тарифа на долгосрочный период регулирования (не менее трех лет). Метод будет применяться для небольших организаций.

Цели введения методов долгосрочного планирования:

- стимулирование привлечения инвестиций;

- повышение капитализации компаний;

- повышение качества стратегического планирования;

- возможность сглаживать последствия реализации ИП в виде изменения тарифов для потребителей услуг;

- создание экономической мотивации снижать издержки, повышать надежность и качество оказываемых услуг;

- минимизация субъективных факторов, определяющих влияние регулирующего тарифы органа на величину тарифов.

\section{Регупяторный договор}

Рассматривая новые методы долгосрочного планирования в отношениях, связанных с регулированием тарифов организаций коммунального комплекса, стоит отметить прежде не применявшийся метод, позволяющий гарантировать соблюдение планируемых для регулируемой организации показателей качества, надежности, капитализации и инвестирования со стороны регулирующего тарифы органа на долгосрочный планируемый период. Такой регуляторный договор - заключаемое между регулируемой организацией и регулирующим тарифы органом соглашение об условиях осуществления регулируемой деятельности, рассматриваемое как механизм процесса тарифного регулирования.

Планируется, что на первом этапе регуляторный договор будет содержать условия осуществления инвестиционной деятельности регулируемой организацией с установлением системы норм и правил, определяемых в первую очередь на федеральном уровне и конкретизируемых путем согласования условий взаимодействия между органами публичной власти и субъектами регулирования.

Существенными условиями регуляторного договора должны стать: ઉффективное

A

нтикризисное

правление 
- обязательства публичных органов, касающиеся:

- ответственности за адекватное планирование и постановку задач;

- соблюдение долгосрочных параметров регулирования;

- установление границ контроля деятельности и соблюдение этих границ;

- последствий наступления непредвиденных обстоятельств;

- неизменности условий подписанного договора на протяжении всего срока его действия, за исключением строго оговоренных случаев;

- ответственность субъекта регулирования за соблюдение показателей надежности и качества продаваемых товаров, услуг;

- соблюдение положений инвестиционной деятельности:

- гарантированный объем инвестиций в установленные сроки;

- обоснование эффективности инвестиций, в том числе достижение показателей надежности, качества, доступности инфраструктуры;

- исполнение обязательств по срокам ввода в эксплуатацию ключевых объектов;

- соблюдение показателей обязательной доли применяемых энергоэффективных технологических решений;

- соблюдение требований к прозрачности деятельности, подтверждаемое в результате обязательной процедуры мониторинга инвестиционных и производственных программ ОКК.

Эффекты использования регуляторного договора:

• для потребителей:

повышение эффективности, надежности, качества, доступности услуг;

- для органов власти:

- установление системы показателей резуль-

татов деятельности ОКК;

- внедрение эффективных механизмов контроля мониторинга деятельности ОКК;

- применение штрафных санкций как средства обеспечения ответственности за надежность и качество услуг;

- повышение прозрачности деятельности ОКК;

- для инвесторов:

- появление дополнительного механизма гарантии возврата вложенных инвестиций посредством снижения возникающих рисков;

- первоначальное определение промежуточных и итоговых целей, которые должны быть достигнуты в результате привлечения инвестиций;

- возможность долгосрочного планирования.

\section{Формы бюджетных и частных инвестиций в объекты коммунапьной инфраструктуры}

С учетом социальной значимости комплекса ЖКХ органы власти заинтересованы в сохранении контроля как за операционной, так и за инвестиционной деятельностью ОКК. Для преодоления данных барьеров возможно применение следующих механизмов:

- участие муниципалитетов в капитале предприятий, реализующих ИП, путем софинансирования инвестиционных проектов с целью сохранить контроль за предприятием;

- закрепление бюджетных инвестиционных обязательств по модернизации объектов инфраструктуры с проведением конкурсов на заключение долгосрочного договора аренды или концессионного соглашения;

- привлечение бюджетных и (или) заемных средств и поручительство органами власти по займам, привлекаемым для реализации ИП в случае привлечения инвестором заемного финансирования.

Виды бюджетных инвестиций, связанных с государственным регулированием тарифов (цен) организаций коммунального комплекса

\begin{tabular}{|l|l|}
\hline \multicolumn{1}{|c|}{ Виды финансирования } & Источник \\
\hline $\begin{array}{l}\text { Бюджетные инвестиции ОКК на реализацию ее ИП в части созда- } \\
\text { ния, реконструкции, модернизации объектов коммунальной инфра- } \\
\text { структуры, находяихся в муниципальной собственности [1, ст. 79] }\end{array}$ & $\begin{array}{l}\text { Бюджет МО, в том числе с учетом межбюджет- } \\
\text { ныхрансфертов }\end{array}$ \\
\hline $\begin{array}{l}\text { Бюджетные инвестиции в уставный капитал ОКК (уставный фонд } \\
\text { МУП, ГУП) на создание, реконструкцию, модернизацию объектов } \\
\text { коммунальной инфраструктуры, находящихся в собственности (хо- } \\
\text { зяйственном ведении) ОКК [1, ст. 80] }\end{array}$ & Бюджет субъектов РФ или бюджет МО \\
\hline $\begin{array}{l}\text { Субсидии ОКК на возмещение целевых расходов в качестве го- } \\
\text { сударственной (муниципальной) поддержки инвестиционной дея- } \\
\text { тельности ОКК в области энергоресурсосбережения и повышения } \\
\text { энергоэффективности (на уплату процентов по кредитам, займам) } \\
\text { [1, ст. 78; 7, ст. 27, п. 1, 2] }\end{array}$ & \\
\hline $\begin{array}{l}\text { Бюджетный кредит ОКК на выполнение отдельных мероприятий, субъектов РФ или бюджет МО } \\
\text { включенных в ИП ОКК [1, ст. 93.2] }\end{array}$ & Бюджет субъектов РФ или бюджет МО \\
\hline
\end{tabular}


стиционным проектам. Для привлечения средств этих инвесторов необходимы детально проработанная ИП и четкое обоснование положительного социально-экономического эффекта от ее реализации. При этом рассматриваются не только показатели инвестиционной привлекательности проекта (например, чистая приведенная стоимость), но и показатели бюджетной эффективности, снижения затрат на оказание услуг, эффект для конечных потребителей (снижение темпов роста тарифов на услуги) и прочие социальные эффекты: повышение надежности, увеличение числа рабочих мест и т.д. С применением данного механизма возможно привлечение государственного (бюджетного) финансирования для реализации проектов, заведомо непривлекательных для традиционных инвестиций. Органы местного самоуправления и органы исполнительной власти субъектов РФ могут предоставлять инвестиции в объекты коммунальной инфраструктуры в нескольких формах (см. таблицу).

Инвесторами, финансирующими инвестиционные проекты в ЖКС за счет внебюджетных источников, могут выступать:

- частные операторы (компании, управляющие активами ЖКХ);

- инфраструктурные инвесторы:

- российские банки, осуществляющие инвестиции в инфраструктурные проекты: государственная корпорация «Банк развития и внешнеэкономической деятельности (Внешэкономбанк)», ОАО «Банк ВТБ»;

- инвестиционные фонды с банковским участием: ОАО «Евразийский» (при участии ВЭБ);

- зарубежные банки: Европейский банк реконструкции и развития, Евразийский банк развития.

По экспертным оценкам, в 2011 году объемы финансирования инвестиционных проектов со стороны крупнейших инвесторов в ЖКХ составили порядка 145 млрд руб. Наиболее значительное финансирование было выделено банками OAО «Сбербанк России» (свыше 60 млрд руб.), Европейским банком реконструкции и развития (свыше 42 млрд руб.) и государственной корпорацией «Банк развития и внешнеэкономической деятельности (Внешэкономбанк)» (около 26 млрд руб.). Крупнейшим частным оператором является ОАО «Российские коммунальные системы».

С учетом общей потребности отрасли в инвестициях становится понятна острая необходимость в удовлетворении требований потенциальных инвесторов к условиям финансирования. Инфраструктурные инвесторы уделяют большое внимание обоснованию инвестиционной привлекательности проекта. МО проявляют заметную консервативность при оценке рисков проекта и имеют ограничения по доле (сумме) вложений в проект, часто предъявляют требования привлечь поручителей по кредиту. Основным вариантом участия инфраструктурного инвестора в проекте является предоставление кредита, реже - участие в акционерном капитале существующих или создаваемых компаний. Также возможно участие в форме предоставления гарантий по кредитам.

К частным операторам относятся компании, управляющие активами ЖКХ, находящимися во владении либо долгосрочной аренде. Соответственно, частных операторов прежде всего интересует вопрос возврата инвестированных средств и получения дохода.

При оценке инвестиционной привлекательности проекта учитывается множество положительных эффектов, далеко не все они могут быть приобретены непосредственно предприятием, реализующим инвестиционную программу (например, снижение затрат). Ввиду этого некоторые положительные эффекты инвестиций могут «выпадать» из доходной базы инвестора. Как показывает практика, для фиксирования распределения положительных эффектов от проекта могут применяться различные договорные модели.

В то же время в результате инвестиционной деятельности возможно возникновение имущества (например, индивидуальных тепловых пунктов), в отношении которого могут быть приняты разные решения (сохранение на балансе, передача другому лицу с заключением договора на обслуживание и т. д.). Для оптимизации управленческих решений в отношении таких активов необходимо моделирование последствий различных решений, их оценка и построение оптимальной договорной модели между контрагентами.

\section{ВЫвОАЫ}

В нашей стране ответственность за развитие инфраструктуры городского хозяйства, социальной сферы несут органы государственного и муниципального управления. Развитие объектов, составляющих эту инфраструктуру, всегда сопряжено с высокими затратами. Во всяком случае размеры финансирования выходят за пределы возможностей региональных и городских бюджетов. Тем не менее решать эти проблемы все равно надо, ведь развитие инфраструктуры напрямую обеспечивает экономический рост. К тому же не на последнем месте стоит и вопрос качества публичных услуг. Поэтому для решения своих задач власть привлекает частный бизнес и вступает в партнерские отношения с ним. Для предпринимателей партнерство с властью означает снижение долгосрочных рисков ведения бизнеса, бффективное

$\Delta$ нтикризисное

правление 
определенные налоговые льготы, престижность реализации инвестиционного проекта совместно с государственными органами.

Для привлечения внебюджетного финансирования в проекты по реконструкции и модернизации уже существующих инфраструктурных объектов и созданы инструменты ГЧП, предусматривающие новые договорные формы владения объектами коммунальной инфраструктуры.

В рамках реализации политики ГЧП законодатели выделили следующие инструменты:
- концессионные соглашения;

- долгосрочные инвестиционные соглашения;

- Инвестиционный фонд Российской Федерации;

- федеральные целевые программы и федеральные адресные инвестиционные программы.

Ввиду того что государственный и частный секторы ведут совместную работу по развитию и модернизации жизненно важных объектов инфраструктуры, в последние годы использование механизмов ГЧП значительно возросло.

\section{Ah}

1.Бюджетный кодекс Российской Федерации от 31.07.1991 № 145-Ф3 // КонсультантПлюс. URL: http://www.consultant. $\mathrm{ru} /$ popular/budget/.

2. О водоснабжении и водоотведении: Федеральный закон от 07.12.2011 №416-Ф3 (ред. от 30.12.2012) (с изм. и доп., вступающими в силу с 01.04.2013) // Консультант Плюс. URL: http://goo.gl/rBdz8.

3.О теплоснабжении: Федеральный закон от 27.07.2010 №190-Ф3 (ред. от 30.12.2012) (с изм. и доп., вступающими в силу с 01.04.2013) // КонсультантПлюс. URL: http://goo.gl/KHqdk.

4. Об основах регулирования тарифов организаций коммунального комплекса: Федеральный закон от 30.12.2004 №210-Ф3 (ред. от 30.12.2012) (с изм. и доп., вступающими в силу с 01.04.2013) // Консультант Плюс. URL: http://goo.gl/rrLOf.

5. Об утверждении Методических рекомендаций по подготовке технических заданий по разработке инвестиционных программ организаций коммунального комплекса: Приказ Минрегионразвития России от 10.10.2007 г. № 100 // КонсультантПлюс. URL: http://goo.gl/itfsL.

6. Об утверждении плана действий по привлечению в жилищно-коммунальное хозяйство частных инвестиций: Распоряжение Правительства РФ от 22.08.2011 № 1493-р (ред. от 04.02.2013) // КонсультантПлюс. URL: http://goo.gl/zSTlO.

7. Об энергосбережении и о повышении энергетической эффективности и о внесении изменений в отдельные законодательные акты Российской Федерации: Федеральный закон от 23.11.2009 №261-Ф3 (ред. от 25.12.2012) // КонсультантПлюс. URL: http:// goo.gl/jwULS.

8. Управление городским хозяйством и модернизация жилищно-коммунальной инфраструктуры: Учебник/Под общ. ред. проф. П. Г. Грабового. 2-е изд., перераб. и доп. М.: ИИА «Просветитель», 2013. 840 с. 